\title{
Maintenance of blood glucose level under intensive mental activities: episodic moderate drinkers versus non-drinkers
}

\author{
Menizibeya Welcome*, Vladimir Pereverzev \\ From $1^{\text {st }}$ International Congress on Neurobiology and Clinical Psychopharmacology and European \\ Psychiatric Association Conference on Treatment Guidance \\ Thessaloniki, Greece. 19-22 November 2009
}

\section{Background}

The benefits of alcohol, especially to the functioning of the hearth and circulatory system have always been recognized by many researchers world-wide [1]. But besides, these positive effects, alcohol use, even in moderate amounts can be detrimental under certain conditions. Several studies have recognized the hypoglycemic effect of alcohol use in excessive doses. Centuries ago, Krebs and fellows admitted that acute alcohol intake in excessive doses results in hypoglycemia $[2,3]$. However, little is still known about the aftereffects of alcohol at low doses, even after a week's interval of moderate drinking.

\section{Aim}

We examine the efficiency of glucose homeostasis control of non-drinkers and episodic moderate drinkers, after approximately one week interval of moderate drinking and under intensive mental activities.

\section{Materials and methods}

The Ethics Committee approved the study protocol and informed consents were obtained from the volunteers after the aims and objectives of the study had been explained. The study took 6-hours (on fasting), involving male students (5 non-drinkers and 8 episodic moderate drinkers that have abstained from alcohol drinks of any composition for at least the last seven days before the study). Blood glucose concentration (BGC) was measured at 2 hours interval, including initial BGC. Various questionnaires - AUDIT, texts and

$\overline{\text { Department of Human Physiology, Belarusian State Medical University, Minsk, }}$ Belarus questions, neuropsychological questionnaires, tests on visual, auditory, operative short-term memory and attention (using Anfimov geometric tables) were used as a measure. The Pearson and Student's t-tests were employed for statistical analysis of results. The probability value for significance was set at $\mathrm{p}<0.05$.

\section{Results}

Significant decrease in the effectiveness of active attention and a faster development of fatigue after 4-6 hours of mental activities in episodic moderate drinkers, compared to non-drinkers was statistically proven. Disorders in episodic moderate drinkers are retained within a period of 7-10 days after moderate alcohol use. The nondrinkers had increasing $\mathrm{BGC}$ in relation to their initial level in all phases of the experiment ( $\partial<0.001$ ). Increase in BGC of alcohol users was observed only within the first 2 hours $(\mathrm{p}<0.05)$. Thereafter, a significant fall in BGC was observed in the 4-6 hrs of the experiment in relation to the BGC of anon-drinkers and its level after 2 hours. Episodic moderate drinkers had 26 times higher errors on various tests than the abstainers $(p<0.001)$. The errors made on various tests increased with decrease in BGC $(r=-0.83 ; \mathrm{p}<0.01)$.

\section{Conclusions}

This is the first study involving male volunteers to show that alcohol use, even episodic (1-2 times/month) in small doses $(23 \pm 8 \mathrm{ml} /$ person/session), after 7-10 days of alcohol intake, is accompanied by long-term glucose homeostasis disorders, leading to cognitive function disturbances and a decrease in the effectiveness of mental activities. Significant decrease in BGC in episodic moderate drinkers was detected in a condition of intensive 
mental activities and was apparent only after 4-6 hours decrease in BGC. Non-drinkers had an increase in blood glucose concentration under the same condition. Disorders in glucose homeostasis control might be the basis of cognitive function disorders in drinkers.

Published: 22 April 2010

\section{References}

1. Catherine LGC: Global status report on alcohol. Geneva. WHO 2004, 1-200.

2. Goodlett CR, Horn KH: Mechanism of Alcohol Induced Damage to the Developing Nervous System. Alcohol Res Health 2001, 25(3):175-184.

3. De Galan BE, BJW Schouwenberg, Tack CJ, Smits P: Pathophysiology and management of recurrent hypoglycaemia and hypoglycaemia unawareness in diabetes. Neth J Med 2006, 64(8):269-279.

doi:10.1186/1744-859X-9-S1-S211

Cite this article as: Welcome and Pereverzev: Maintenance of blood glucose level under intensive mental activities: episodic moderate drinkers versus non-drinkers. Annals of General Psychiatry 2010 9(Suppl 1): S211.

Submit your next manuscript to BioMed Central and take full advantage of:

- Convenient online submission

- Thorough peer review

- No space constraints or color figure charges

- Immediate publication on acceptance

- Inclusion in PubMed, CAS, Scopus and Google Scholar

- Research which is freely available for redistribution

Submit your manuscript at www.biomedcentral.com/submit 